\title{
Natural Philosophy and Natural Logic
}

\author{
Kun $\mathrm{Wu}^{1, *}$ and Zhensong Wang ${ }^{2}$ (D) \\ 1 International Information Philosophy Research Center, Xi'an Jiaotong University, \\ Xi'an 710049, Shaanxi, China \\ 2 Philosophy Department, School of Humanities and Social Sciences, Xi'an Jiaotong University, Xi'an 710049, \\ Shaanxi, China; zhensong1167@gmail.com \\ * Correspondence: wukun@mail.xjtu.edu.cn
}

Received: 30 July 2018; Accepted: 17 September 2018; Published: 21 September 2018

\begin{abstract}
Nature has its own logic, which does not follow the human will. Nature is itself; it exists, moves, changes, and evolves according to its own intrinsic ways. Human and human society, as a product of a specific stage of natural development, can only be a concrete manifestation of the logic of nature. 2. In the broad sense, nature refers to all, both phenomena and processes, in the universe. It includes human society spiritual phenomena. In a narrow sense, nature refers to the world outside the society and opposed to society as well, or refers to the research objects of natural sciences. 3. The narrow natural philosophy is in the intermediary position between the natural sciences and the overall philosophy (the supreme philosophy, an advocation of Kun Wu's philosophy of information. For further detail, please refer to the subscript in the following.). Furthermore, it is an independent sub-level philosophical discipline; the broad natural philosophy is a meta-philosophy or supreme philosophy, stipulating the entire world from the dimensions of nature itself. 4 . Natural philosophy reveals the laws of nature's own existence, movement, change, and evolution. This determines that the way of expressing natural philosophy is necessarily natural ontology. The construction of the theoretical system of natural philosophy is inevitably a process of abandoning cognitive mediums of human beings through reflection. It is necessary for us to conclude that natural philosophy is the stipulation of nature itself, which comes out of the nature itself. So, we must explain the nature from the standpoint of the nature itself. 5. The true philosophy should move from the human world to the nature, finding back Husserl's suspended things, and establish a brand-new philosophy in which man and nature, substance, information, and spirit are united. This kind of philosophy is able to provide contemporary ecological civilization with a reasonable philosophical foundation, rebuilding natural philosophy in a new era, which is a very urgent task for contemporary philosophers. 6. The unity of philosophy and science cannot be seen merely as an external convergence, but also as an intrinsic fusion; a true philosophy should have a scientific character, and science itself must have a philosophical basis. The unity of such an intrinsic fusion of science and philosophy can be fully demonstrated by the practical relationship of development between human philosophy and science. 7. In addition to the narrow path along epistemology, linguistics, and phenomenology, the development of human philosophy has another path. This is the development of philosophy itself that has been nurtured and demonstrated during the development of general science: On the one hand, the construction of scientific rationality requires philosophical thinking and exploration; On the other hand, the progress of science opens the way for the development of philosophy. 8. In the real process of the development of human knowledge, science and philosophy are regulated, contained, and merged with each other in the process of interaction. The two are inlaid together internally to form an interactive dynamic feedback loop. The unified relationship of mutual influence, regulation, promotion and transformation presented in the intrinsic interplay of interaction between science and philosophy profoundly breeds and demonstrates the general way of human knowledge development: the philosophicalization (a term used in Kun $\mathrm{Wu}^{\prime}$ s philosophy of information. For more details please see in Kun Wu, 2016, The Interaction and Convergence of the Philosophy and Science of Information, https://doi.org/10.3390/philosophies1030228) of science and scientification (a term used in Kun
\end{abstract}


Wu's philosophy of information. For more detail, please see in $\mathrm{Kun} \mathrm{Wu}, 2016$, The Interaction and Convergence of the Philosophy and Science of Information, https://doi.org/10.3390/philosophies1030228) of philosophy. 9. We face two types of dogmatism: one is the dogmatism of naturalism, and the other is the dogmatism of the philosophy of consciousness. One of the best ways to overcome these tendencies of dogmatism is to unite natural ontology, and epistemic constructivism. The crisis of contemporary philosophy induced by the western consciousness philosophy seems like belonging to the field of epistemology, but the root of this crisis is deeply buried in the ontology. The key to solving the crisis of contemporary philosophy lies precisely in the reconstruction of the doctrine of natural philosophy centering to the nature itself and excluding God. The task to be accomplished by this new natural philosophy is how to regain the natural foundation of human consciousness after the God has left the field. 10. Since the 1980s, the philosophy of information established and developed in China has proposed a theory of objective information, as well as the dual existence and dual evolution of matter and information (a key advocation in the ontological theory of Kun Wu's philosophy of information). It is this theory that has made up for the vacancy existing between matter and mind, which apparently exists in Cartesian dualism, after the withdrawal of the God's from the field. Philosophy of information in China is first and foremost a natural philosophy that adheres to naturalistic attitudes. Second, this natural philosophy explains the human, human mind and human society in the interpretation of the process and mechanism of natural evolution. In this connection, philosophy of information (a key advocation of Kun Wu's philosophy of information) in China is a system of meta-philosophy or supreme philosophy. This system undoubtedly has the nature of a new natural philosophy. At the same time, this philosophy can better reflect the philosophical spirit of the information age.

Keywords: natural philosophy; the logic of nature; ontology; epistemology; in the name of nature; philosophy of information

\section{The Analysis of the Subject}

The title of this article refers to "the logic of the nature". It is necessary to give a reasonable explanation to the word logic used here. The word logic derives from the Greek word Logos. The original meaning is thought, thinking, reason, and language. With the development of language, the word Logic has gradually become a more abundantly meaningful word. At present, for the meaning of the word logic, we can at least find the following four different stipulations: (1) the laws that represent the development of objective things, such as "the logic of the development of things" and the "logic of social development"; (2) the rules of thinking, such as "thinking must be logical" and "reasoning logically"; (3) representing science that studies the form of thinking and its laws, which is logic, such as "formal logic", "dialectical logic", "mathematical logic"; (4) Represents a particular position, point of view, and inference (argumentation) method, such as "absurd logic" and "jerk logic." [1].

The ambiguity of the word logic makes it necessary for us to explain the meaning of the word in terms of the logic of the nature involved in the title of this article. The word "logic" used in the title of this article does not mean that there is an "objective ideal", "absolute spirit", or supreme existence of the "God" behind the nature, nor is it to refer to the rules exiting in human mind and cognition. Here we follow the first provision of the word logic listed above, emphasizing an idea that nature has its own objective logic, which neither bases on nor changes with human will. Nature is itself, and it exists, moves, changes, and evolves through its own intrinsic ways. In this thinking, we also include such a view: human beings and human society as a product in a specific stage of natural development, it can only be a concrete manifestation of the logic of the nature [2].

The discussion about the logic of nature can be carried out on two different levels: one is the level of natural sciences and the other is the level of natural philosophy. The former usually refer to various 
natural sciences, while the latter is often carried out in a framework called "natural philosophy". The focus of this article is to explore the rationality of natural philosophy and its compatibility and unity with the natural sciences.

\section{Modern Scientific System}

To explore natural philosophy, we must first explain its nature and scope.

On the basis of the scientific paradigm provided by the theory of complex information systems, any research object can only be clearly defined in the relationship of the relevant overall system network. To determine the nature and scope of natural philosophy, it is first necessary to place it in the system of modern science to regulate and recognize it.

Science as a system for cognizing, reflecting, and constructing the object world always has an isomorphic relationship with the object world that it cognizes, reflects, and constructs. The object world is a world that has entered human cognition. Through the different stages of scientific history, the specific forms of the isomorphic relationship between scientific systems and the corresponding object worlds that are cognized, reflected, and constructed by the scientific systems have been changing. Consequently, the specific patterns of people's cognition to the object worlds have been changing accordingly. It indicates the clues and venations of incessant evolution of the ability of human beings' scientific understanding and the continuous development of science and technology.

The structural model of the modern scientific system embodies the general principles of the scientific paradigm provided by theory of complex information systems. This means that everything is a system, and all systems are integrated, hierarchical, and have the basic characteristics of universal interaction through internal and external networks of materials (including mass and energy) and information flow. As a whole network system, the modern science system must also exhibit the corresponding characteristics of the general system, namely integrality, hierarchy, constitutive property and the universality of interaction.

Figure 1 indicates the structure of modern science on the macro level.

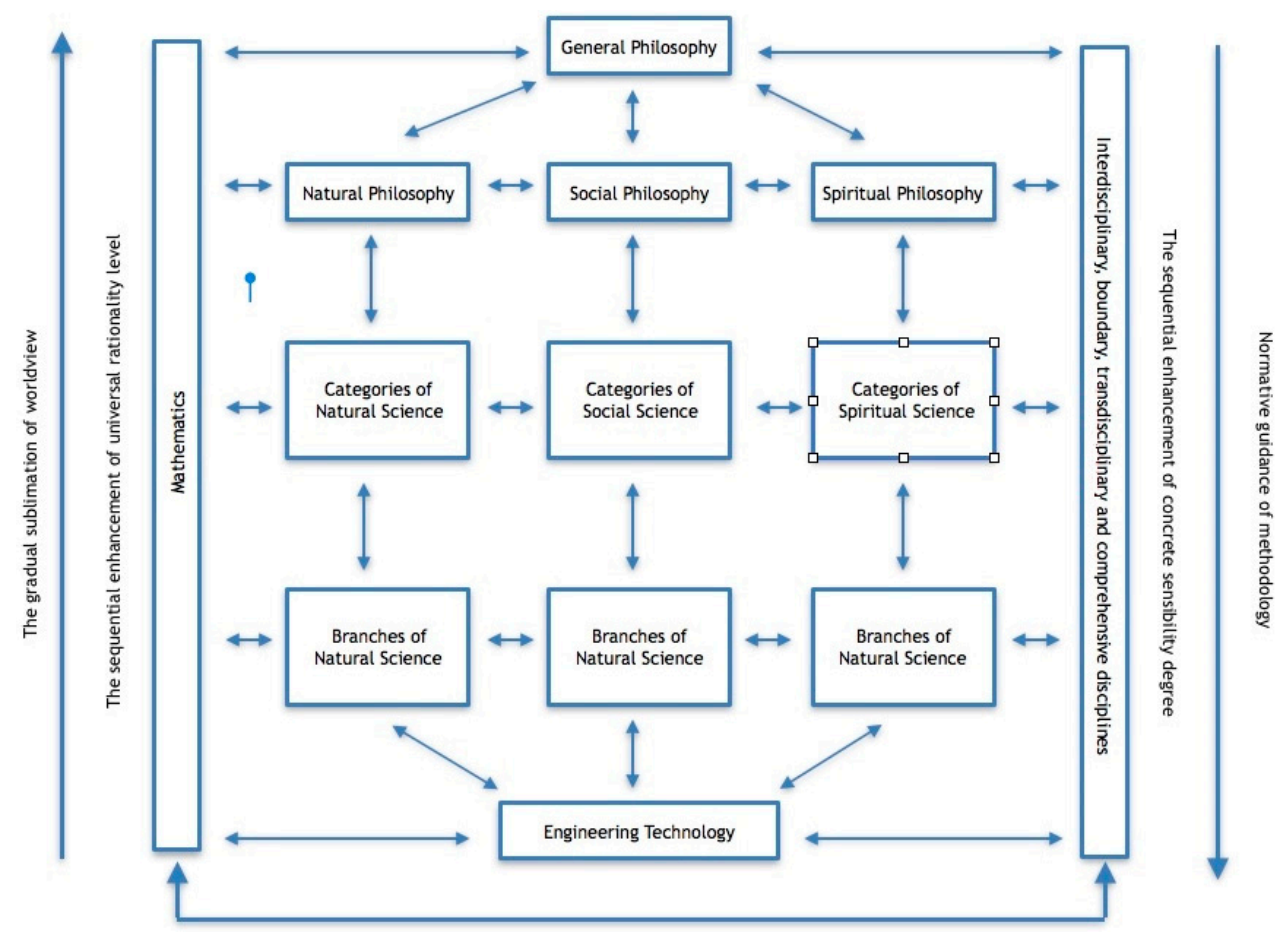

Figure 1. The Structure of Modern Science [3].

The following is an explanation for Figure 1. 
2.1. The General Philosophy is the Science that Studies the General Nature of the Whole World and the General Laws of Movement, Change, and Development

The world, as a whole, is the largest and highest system. The disciplines that take this whole system as the object of study and reveal its overall nature and the general laws of movement, change, and development constitute the philosophy in an overall meaning and at the highest level. It can be called general philosophy, supreme philosophy or meta-philosophy. From the perspective of the history of philosophy and the situation of contemporary philosophy, general philosophy has always led to a large number of schools of thought.

\subsection{The Philosophy of Nature, Social Philosophy, and Philosophy of Mind in a Narrow Meaning Are Sub-Disciplines under the General Philosophy}

In general, the scientific community always distinguishes the existence world (in the philosophy of information advocated by Wu Kun, "the existence world" is a term referring to everything that exists, including the matter, mind and information. For more details, please see in Kun $\mathrm{Wu}$ and Joseph Brenner, 2017, Philosophy of Information: Revolution in Philosophy. Towards an Informational Metaphilosophy of Science, https: / / doi.org/10.3390 / philosophies2040022; Kun Wu, 2015, The Development of Philosophy and Its Fundamental Informational Turn, https:/ / doi.org/10. 3390/info6040693; Kun Wu, 2012, The Essence, Classification and Quality of the Different Grades of Information, https://doi.org/10.3390/info303040) from the general sense, to the three basic fields: the nature, human society and mental worlds. Corresponding to these three fields, the natural philosophy, the social philosophy, and the philosophy of mind separately treats one field as its study object, revealing the overall nature of the field and the general laws of movement, change, and development within it. Because these three philosophical disciplines each use one of three basic fields as their research objects, they can only be sub-disciplinary philosophies under general philosophy, studying the whole existence world. Whether from the perspective of the history of philosophy or from the situation of contemporary philosophy, such sub-disciplinary philosophies also have many different schools of thought. It is necessary to emphasize that the differences among natural philosophy, social philosophy and philosophy of mind should not be viewed merely as differences in the fields of study, but rather, as differences in the directions of research. If we start from the general concept of nature, the social and realms of mind both are special natural fields developed from the evolutionary course of the nature. In this sense, the general concept of nature is higher than the concepts of society and mind, and holographically contains them. The aforementioned stipulation of natural philosophy as a sub-level philosophy juxtaposed with social philosophy and philosophy of mind bases on a narrow concept of nature. If we proceed from the general concept of nature, we can establish a general philosophy of nature. And the general natural philosophy can be a meta-philosophy or a supreme philosophy that stipulates the whole world from the dimension of the nature itself. We will discuss this point in the fourth section of this article.

\subsection{Categories and Branches of Science}

In the natural world, human society and the realm of mind, different object areas can be distinguished. The study of the characteristics and laws of these different target areas leads to more specific scientific disciplines. At this level, the more general discipline is the categories of science, and the discipline that is further differentiated under the categories of science is branches of science. In terms of the development of modern science, physics, chemistry, biology, geology, and astronomy ... belong to the category of natural sciences; ethnology, economics, politics, law, ethics..., belongs to the category of social sciences; logic, psychology, intelligent science ... belongs to the category of science of mind. The development of modern science presents a trend of being highly differentiated and highly integrated. In the highly differentiated direction, some sub-disciplines that have reclassified under the category of science have reached the fifth, sixth, and even seventh levels. In the highly integrated direction, on the one hand, it manifests itself in the emergence of new holistic disciplines 
in the synthesis of multiple disciplines. On the other hand, it produces various types of marginal interdisciplinary sciences in the process of scientific deep differentiation. This is the synthesis that emerged in the differentiation.

\subsection{Engineering and Technology}

Engineering is the discipline that applies the relevant scientific principles and methods to the direction, transformation, or control of the object world, and relates to the skills and methods of producing and using the corresponding tools. Obviously, engineering technology itself can also be divided into different areas or levels. In the horizontal direction, we can distinguish some major fields such as natural engineering technology, social engineering technology, and thinking engineering technology. In the vertical direction, we can at least distinguish two levels of basic engineering technology and applied engineering technology. The former is the discipline of skills and methods for the production and use of tools that act on general objects, while the latter is the discipline of skills and methods for the production and use of special tools that are applicable to certain specific sectors, industries, or objects. In the latest research trends, some scholars try to make a clearer distinction between technology and engineering: technology is the way and method of transforming the object world; engineering is the practical activity of creating and constructing new social beings.

\subsection{The Mathmatics Is a Tool at a Special Status}

People often see mathematics as a natural science, which is just as much of a misunderstanding as thinking of philosophy as a social science. Actually, mathematics reflects the abstract relationship of numbers and shapes existing universally in nature, society, and mental world. Therefore, it cannot be regarded as a natural science, nor can it be regarded as an integral part of social science and science of mind. Mathematics can be regarded as an omnidirectional discipline with relatively independent development characteristics. It can provide a powerful scientific tool of quantitative description for the study of natural sciences, social sciences, spiritual science, and philosophy.

\subsection{Interdisciplinary, Borderline, and Transdisciplinary and Comprehensive Disciplines}

The object world (a term used in Kun Wu's philosophy of information. For more detail, please see in the references mentioned in the previous subscript) people know is always in a complex and ever-changing relationship of mutual connection, mutual penetration, mutual regulation and mutual transformation. If the research on the object is only from large or small-scale perspective, it is still a simple mechanical research method with the characteristics of the reductive analysis method. This research method obviously lacks the needed comprehensiveness and scientificity for the study of things in the complex and integrative relationship. Since the middle of the 20th century, with the increase in the complicatedness of the problems faced by mankind and the accelerating development of modern science, a number of new disciplines has emerged, which have the complex and comprehensive relationships as their research objects. These emerging disciplines often cannot be simply subordinated to one the fields of natural science, social science or science of mind. They essentially exhibit the characteristics of domain intersection, marginal integration, transversal relationship, and complex omnidirectional features. For example, information science, systems science, self-organization science, chaos and complexity research, life science, ecological science, space science, ocean science, environmental science, cognitive science, and so on.

\subsection{The Unity of Ontology and Methodology}

The bottom-up arrow on the left in Figure 1 indicates discrepancy of disciplinary abstraction at different levels. It also indicates the ontological magnitude of different levels of disciplines. The top-down arrow on the right in Figure 1 indicates the methodological role of higher-level disciplines in paradigmatic guidance for lower-level disciplines. It also shows the differences in specific degree of sensibility of disciplines in different levels. These two reciprocal arrows clearly symbolize 
the concrete and realistic unity of ontology and methodology. The philosophy we usually refer to is both ontological and methodological, and it establishes on the two reciprocally reversed directions.

\section{The Nature and Developmental Situation of Natural Philosophy}

Judging from Figure 1, philosophy also has a systematic hierarchy. In Figure 1, according to the degree of general abstract understanding of the law of the development of things, two levels of philosophy are distinguished: the first level is general philosophy; the second level (sub-level) has three major paralleled philosophical disciplines - natural philosophy, social philosophy, and philosophy of mind. Of course, the systemic hierarchy of philosophy is not just these two levels. Under natural philosophy, social philosophy and philosophy of mind, some more specific lower-level philosophical disciplines can still be distinguished. We use Figure 2 to mark this kind of systematic hierarchy of philosophy.

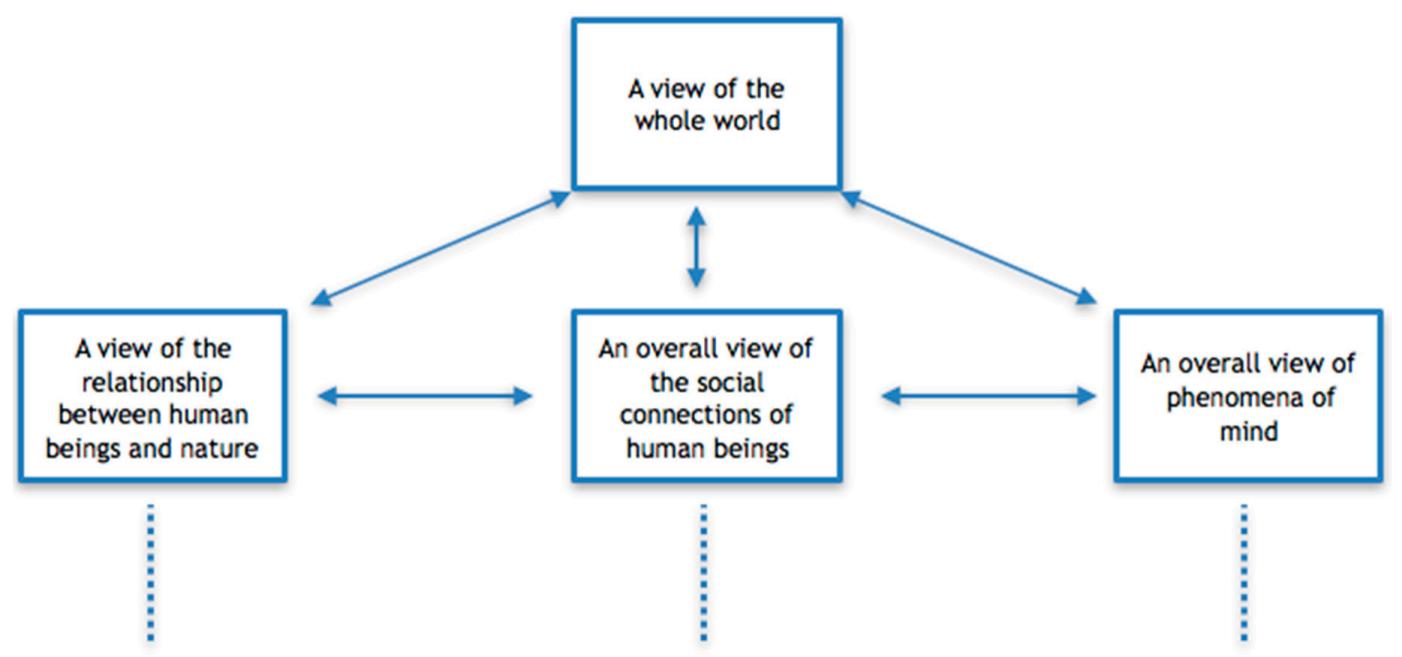

Figure 2. The Hierarchy of Philosophy [3].

From Figures 1 and 2, it is not difficult to see that natural philosophy is in the middle of the natural sciences and the general philosophy, and it is an independent sub-level philosophical discipline.

In the discussion of the previous section, we considered natural philosophy as a philosophical discipline that takes the whole nature as its object, revealing the essence of nature and the general laws of its movement, change, and development. In Figure 2, we also use the "overall view of the relationship between the man and the nature" to make provision for natural dialectics. However, the above two provisions are still relatively general and abstract, because people's understanding on the general quality and laws of nature and the general view on the relationship between man and nature are achieved through the intermediary of science, technology, and engineering. Science is the way and method of understanding the world. Technology is the way and method of transforming the world. Engineering is the concrete activity of transforming the world. This means that people reveal the overall quality and general laws of nature and deal with relationship between man and nature through knowing and transforming the nature. Thus, the levels and patterns that people realize the general laws of nature have to rely on the level and pattern of the development of science, technology, and engineering, and the relationship between human and nature naturally contains triple specific contents: First, people use the whole natural world as the research object, and specifically construct the relationship in the corresponding natural landscape; second, human beings get to know the natural world through concrete research behavior in natural science; human beings get to transform the natural world through technological methods and engineering activities.

It is based on the triple real relationship between man and nature as mentioned above that we have reason to identify the research object of natural philosophy as three specific aspects: the whole natural world, the whole natural sciences, and the overall technology and engineering activities. Or, 
we can also say that natural philosophy has the overall relationship between man and nature as its object, including the relationship of constructing natural model, the relationship of knowing the nature, and the relationship of transforming the nature.

In the same way, we also have reason for the following definition: natural philosophy is a philosophy about the nature and of knowing and transforming the nature. If this definition is more concretely developed, it is: philosophy of nature is a philosophical theory of the general quality, existential way, and development laws of the nature, natural science, and technology engineering activities.

From the above discussion, we have reason to determine the disciplinary content or disciplinary system of natural philosophy as four more specific aspects: philosophy of nature (natural landscape), philosophy of science, philosophy of technology, and philosophy of engineering.

Natural philosophy has a broad sense and a narrow sense. The natural philosophy listed in Figure 1 as sub-level philosophy, alongside social philosophy and philosophy of mind, is a natural philosophy in a broad sense. The broad sense philosophy of nature includes not only the philosophy of constructing and describing the natural landscape, but also the philosophy of science, philosophy of technology, and philosophy of engineering that know the intermediary approaches of reaching this construction and description. The narrow sense of natural philosophy refers only to the philosophy of constructing and describing the natural landscape, which has the whole model of the natural world as its specific object of study. It is a philosophical theory about the natural landscape, patterns, and the general laws of its development. Perhaps using the "view about the nature" and "natural landscape" to refer to the narrow natural philosophy is more apropos.

In the long course of development of science and philosophy, natural philosophy has also experienced different historical forms. The ancient natural philosophy is integrated with the ancient natural sciences, and its core mission is to explore the ontological queries of the natural world and the relevant description of the world landscape. Since natural philosophy at that time could not be based on empirical science, it was always intuitive and speculative. With the modern sciences gradually diverging from philosophy, some philosophers tried to establish a theoretical system about the natural world and beyond the natural sciences based on abstract speculation, according to certain materials provided by scientific development at that time. From the early 18th century to the early 19th century, natural philosophies in German classical philosophy, especially Hegelian natural philosophy, were outstanding representatives of this kind of natural philosophy. This kind of natural philosophy uses human ideological construction to surpass the history of human knowledge and to transcend the revealed quality of nature by empirical science. Therefore, it is clearly contrary to the development of science itself.

Since the 20th century, with the rapid rise and in-depth development of modern science represented by theories of relativity, quantum mechanics, modern cosmology, molecular biology, information science, systems science, complexity science, and intelligent science etc., a worldview of information system and complex integration based on relevant facts, theories and scientific paradigms provided by modern sciences has been gradually established and showed to us. It is such worldview of information system and complex integration that has become a new historical form of natural philosophy that matches our times.

\section{About "Natural World"}

The concept of "nature" can usually be interpreted in two ways. The broad sense naturally refers to all things, phenomena, and processes in the universe. It includes human society and mental phenomena. It is a concept having the same scale as the concepts of universe, world, and the existence in a broad sense. The narrow sense of nature refers to a world outside the society that is opposed to society. Or the general object world of natural science research.

It is a controversial issue that the category of "nature" should be interpreted broadly or narrowly in natural philosophy. More natural philosophers understand the nature from a narrow sense. 
People who insist on such narrow understanding are likely to think that the entire field of existence can distinguish three parallel areas, which are nature, society, and thought. The nature is the part that exists outside the society (including thought) and opposes to, parallels to and distinguishes from the society (including thought)

Those who insist on broad understanding think that society (including thought) is a product of natural evolution and a special state of natural development. It should be included in nature and governed by the general laws of nature. Therefore, the law of nature must include the most fundamental aspects of the development laws of society (including thought). Therefore, the category of "nature" should be understood in a broad sense in natural philosophy.

We agree that in the philosophy of nature a broad understanding of the category of nature should be adopted. But this requires a few explanations:

\subsection{Society (Including Thoughts) Is a Special Part of Natural History}

In the direction of its evolution, the nature presents a series of evolutionary stages: primitive fireballs $->$ nebulae $->$ galaxies $->$ fixed stars $->$ planets ... As far as the general evolutionary process of nature is concerned, the planet can be seen as its advanced development stage. Only on extremely few planets can it be possible to form conditions for the evolution to a higher stage of material development. Fortunately, the earth on which we live is just such an extremely lucky planet, and it is also the only basis for us to understand these higher levels of material development. According to the current situation of the Earth's evolution, this higher material development can be roughly divided into three stages: organic sphere -> biological sphere-> human society (including thought). These three stages of development can only belong to the evolutionary history of the planet Earth itself. The formation and development of human society is the highest product of the planet's evolution. Society is also part of the nature in broad sense. Of course, society (including thought) is also a special part of the nature. It has a series of new properties compared to all other parts of the nature.

\subsection{Society (including Thoughts) Can Only Exist and Develop on the Condition of Obeying Natural Laws}

Nature is an area that is more universal than society and thought. Society is a special item of nature. Thought is a special part of society. Although, as a special natural field, society has some specific operating rules that are different from all other natural fields. However, in any case, society cannot violate the laws of nature. The development of human society has so far not been able to change the mechanic movement rules of planets which the earth obeys. It is still unknown whether human society can have this capability in the future. There have been no results regarding the existence of aliens or even communication with them. As an evolutionary phenomenon of the Earth, human society has been playing a relatively important role in the Earth's biosphere. However, with such a small area of the Earth's biosphere, humans must also follow the basic operational laws of the biosphere. Any deviant behavior that ignores these laws will be relentlessly punished.

\subsection{Natural Philosophy Examines Society and Thinking from the Perspective of Natural Qualities}

The general view is that the differences among natural philosophy, social philosophy and philosophy of mind lie in the different fields of their research and generalizations. Natural philosophy studies the general problems and laws in the natural world (narrow sense). Social philosophy studies the general problems and laws in human society. Philosophy of mind studies the general problems and laws in thoughts. In fact, this view is extremely superficial. The differences among the disciplines of natural philosophy, social philosophy and philosophy of mind should not be viewed merely as a difference in field of study, but rather as a difference in the angle and direction of doing research. From the perspective and direction of nature, society and thought are by no means outside the realm of nature. The investigation on society and thoughts by natural philosophy takes place from the standpoint of inherent quality of nature, but neglecting the more individual or specific details in society and thought. The difference between generality and particularity constitutes the difference disciplinary 
differentiation among natural science, social science and science of mind. Although social philosophy studies the special laws of social operation, at the same time, it must inevitably examine the natural origins of society and the general aspects relates to nature. This is also true for the philosophy of the mind. When examining phenomena of thinking, it must also examine its natural and social origins, attributes, and so on. Reasonable conclusions can only be this: nature, society, and thought are by no means isolated from each other. All three are "holographic mapping" the other two fields or aspects from their own perspectives and directions.

Although we classify it according to the existing philosophical disciplines, we consider natural philosophy, social philosophy, and philosophy of mind as three parallel sub-level philosophical disciplines. However, if we look from the perspective of broad sense nature and "holographic mapping," natural philosophy must be higher than social philosophy and philosophy of mind, because society and mind are the areas derived from the development of nature, and nature is the mother and foundation of the existence and development of society and mind.

\subsection{Society Is the Core Part of "Humanized Nature"}

Obviously, as a special part of nature, the society is a natural field with new qualities and is a natural field that the human beings lives in and influences. In this sense, society is a natural part that has been humanized. The human factor is nothing more than knowing and transforming the nature. We have reason to regard humanized nature as the general name of the part of nature that has been known and transformed by human beings. Although not all natural areas that humans have come to know can be incorporated into the social sphere, society is, after all, a core part of this "humanized nature". Along with the increase of the ability of human beings to know and to transform the nature, the breadth and depth of humanized nature (including human society) will also grow. Human society has been treated here as a natural field with new qualities. At the same time, it has also been seen as a self-organizing system that develops itself.

\subsection{In the Infinite Track of Natural Movement and Development, Human Society Is Merely a Trivial, Accidentally Generated, Transient Event}

For nature, human beings can only be a small, insignificant and minor influential parameter, which is small enough to be completely negligible. In any case, society and thinking, as the highest form and an attribute of the development of nature, are an ability of natural seed hiding in the nature eternally, and this ability of nature will never disappear.

That is the case. No matter how advanced the society and thinking ability are, they still can only exist in the iron necessity of nature, rather than being beyond or on the top of it. If we say that from the perspectives of society and thoughts themselves, society and thoughts also have certain elements that are independent from nature, but from the perspective of the nature, this external independence is gone. What natural philosophy adopts is a method investigating from the perspective of the nature. This method requires us to grasp the trajectory of the overall operation of the nature in the unity of nature, society, and thought.

\subsection{Natural Nature and Artifical Nature}

Depending on the influence of human beings, the academic community divides nature into two categories: one is natural and the other is artificial. Natural nature is the entire world before human beings appear. Later, human beings had come to exist from the evolution of natural nature. At the same time, the society and artificial nature derived from the natural nature. Natural nature is nature that has not been transformed by manpower. It had been existing before mankind was born, and has been existing as the foundation of artificial nature after mankind was born; artificial nature is the nature that natural nature changes under the influence of mankind. Diachronically, natural nature is the first nature and artificial nature is the second nature. 


\section{The Exposition of the Method of Natural Philosophy}

On the explanation of natural logic, we are obviously in a situation of dilemma: On the one hand, the logic of nature is purely free and objective; on the other hand, the expression of natural logic can only be mediated by human subjective understanding. Such an intermediary characteristic makes the level and pattern that the expression of natural logic can achieve has a certain dependence on it, so that it cannot be separated from the level and pattern of this medium's development. In this sense, the expressed natural logic must use the cognitive structure of the expresser as its own frame of reference, which inevitably brings some epistemological features to the expressed natural logic. Here, objective laws cannot be revealed at a purely objective level. From the perspective of the history of human understanding on the nature, the dependence of the expressed degree of natural logic on the level of human cognition is quite obvious. With the continuous development of human cognition, it also brings about the incessant change of the natural mode of human cognition.

Although the specific state of the natural model has a dependence on the level of human cognition, we can still distinguish the natural logic from the human cognition itself. Here, logic is about nature, but is not about human cognition itself (a certain unity of subjective logic and objective logic is another problem). For example, our description of the movement laws of celestial bodies is not about human cognition. Although this description passed through the medium of human cognition and some kind of transformation, distortion, selection, or reconstruction occurred while being mediated, this description was ultimately reflected in nature itself. Here, it is itself, rather than the knowing, that nature regulates through the medium of cognition. This gives us an insight: the expression of natural logic must adopt a method that is relatively external to human cognition.

From the perspective of philosophical methodology, ontology and epistemology are two of the most macroscopic methods of philosophy. They stipulate two different angles and directions in which we examine the problem. Ontological methods can be divided into human-based and nature-based. Although the study of natural philosophy has to base on human cognition, the expression of natural philosophy should not adopt epistemological methods, nor should it adopt human-based methods. Because natural philosophy reveals the objective laws of nature's own existence, movement, change, and evolution, this determines that the way of expressing natural philosophy has to be naturally ontological. Although the disclosure of objective logic must be based on human subjective understanding, and the construction of the theoretical system of natural philosophy must be mediated by the general achievements of science, technology, and engineering activities, as far as natural philosophy itself is concerned, it is neither equal to human existence theory and human epistemology, nor directly related to scientific epistemology, scientific methodology, technical epistemology, technical methodology, engineering activity theory, engineering methodology and so on. The construction of the theoretical system of natural philosophy is inevitably a process of abandoning human cognitive influence through reflection. On the basis of discarding the medium, it is necessary for us to conclude that natural philosophy is a kind of stipulation about itself from nature itself. In this sense, we must express nature in the name of the nature. Of course, "in the name of nature" must also be mediated through the medium of human cognition, and must also be subject to the constraints and regulations of this medium. The so-called ontological investigation of philosophy does not mean that it can naturally proceed without human cognition. It means that human beings, relying on their own understanding, explore the true essence of the existence, movement, change, and development of the nature itself, which is external to human cognition. In this search, human cognition has been recognized as the phenomena presented at a particular historical stage of natural evolution.

We have noticed that in modern times, especially since the development of the contemporary western consciousness, philosophies have embarked on a path of rejecting natural philosophy. In particular, the phenomenological trend of thought that has had the greatest influence in contemporary times is the rejection of natural philosophy as its highest program. The founder of phenomenology, the German philosopher Edmund Husserl (1859-1938), presupposed the "suspension" of nature and the "exclusion" of naturalism attitudes when constructing his philosophy of intentionality. And the content 
of its "suspension" and "exclusion" is so broad: everything outside the consciousness, including natural and social objects, cultural and social products, and the whole life, human, and community, and the objectivistic attitudes based on these things is included as well [4]. After that, the French philosopher Merleau Ponty (1908-1961), who used the phenomenological method to propose the philosophy of the body, regained the human body suspended by Husserl, trying to explain the phenomenon of human consciousness by combining body and mind. However, the field of his research is still limited to the world of human beings and the world of human mental activities. We maintain that true philosophy should move from the human world to the nature, find back everything that is suspended by Husserl, and establish a brand-new philosophy in which man, the nature, matter, information, and mind are united together. Such philosophy can provide contemporary information ecology civilization a reasonable philosophical foundation. In this way, in the development of philosophy in the future, based on the new achievements in the development of contemporary science, technology, and engineering, reinterpreting the essence of nature in the name of nature and rebuilding the natural philosophy of a new era, which must be an urgent task for contemporary philosophers.

\section{Natural Philosophy and Natural Science}

As we mentioned in the first section of this article, the discussion on natural logic can be conducted at two different levels, natural science and natural philosophy. This inevitably leads to a question: What is the relationship between these two levels? This problem is similar to the so-called "problem of the relationship between science and philosophy."

In our time, philosophy and science are clearly separated from each other in their manifestations. There is now a discussion about the relationship between science and philosophy, more in the sense of being separated from each other, or simply in the sense of unity of external relations. The discussion in this section will explore another view that is contrary to or different from the views of separation and external unity of science and philosophy.

As early as 1991 and 2004, Kun Wu has published two articles devoted to the relationship between science and philosophy. The titles of the two articles are "The level and the transition of level-the internal unity of science and philosophy" [5] and "A discussion on the relationship between science and philosophy." [6].

In these two papers, the author emphasizes the view that philosophy is the pursuit of universal rationality by human beings. However, universal rationality and specific sensibilities cannot be completely separated in human cognitive activities; science is constituted by universal rationality in nature. These principles are not equal to the direct presentation of some observations and experimental facts, and the rise from various factual statements to the principle of universal rationality depends on the ideas, rules and methods of a certain philosophical thinking. Any scientific universal reason is correspondingly infiltrated with a philosophical concept, and this scientific universal rationality has reason to be seen as a product of a combination of philosophical ideas and concrete statements. In the abstract of the article "A Discussion on the Relationship between Science and Philosophy", Wu Kun wrote: "The unity of philosophy and science cannot be seen merely as an external connection, but also as an intrinsic fusion; the inseparability of universal rationality and specific sensibility in human cognition activities is the ultimate basis for the internal unity of philosophy and science; the inherent hierarchical differences in the universal rationality stipulate the level of science or philosophy, and the relative demarcation between philosophy and science. The transition from low-level general rationality to high-level general rationality and the elimination of limitation and the excavation of the universal characteristics of the high-level rationality exerting on the low-level rationality constitute a scientific transformation of philosophy and a philosophy-to-science criticism. Through critically accepting the low-level universal rationality, philosophy changes its old ideas, theories or systems, which constitutes a process of self-criticism in the development of philosophy."

In fact, true philosophy should have a scientific character, and science itself will certainly have a philosophical charm. To say that philosophy should have a scientific character does not mean 
that philosophy is a vassal to science, nor does it mean that philosophy is equated or attributed to general science. Philosophy has a dual relationship to science. One is based on its rationale, and the other is beyond it. Based on rationale, philosophy cannot ignore the development of science, nor can it violate the general principles of science. What goes beyond this is that the general principles of philosophy for science should not simply remain at the level of specific sciences, because the relevant theories explained by specific sciences are often constrained by the fields, levels, perspectives, and purposes of which they are examined. These corresponding constraints bring about certain limitations to the related theories of specific sciences. To reveal the more general nature of things, it is necessary for philosophy to analyze, overcome and eliminate the narrow limits of specific science, which is philosophy's criticism on science. What is achieved on the basis of this criticism is philosophy's transcendence to science. In addition, the infinite nature of the universe and the limitation of the existence of human beings and the development of science stipulate our scientific understanding on the universe. It is always a limited understanding about the infinite: limited fields, limited levels, limited angles, limited vision, limited phases... In this way, human science always has an endless mission with respect to the infinite world. such a situation of science poses a contradiction to the general rationality that philosophy seeks. The way to resolve this contradiction is philosophy's criticism and transcendence to science. Through this criticism and transcendence, philosophy can liberate from the shackles of concrete sciences and obtain higher levels of freedom. Through free thinking, philosophy breaks through the boundaries of science, and wisdom is used to bridge the gap between the concrete sciences and general rationality. Therefore, compared to specific science, philosophy has a higher level of freedom.

The philosophical criticism on science and the scientific transformation on philosophy make philosophy and science no longer separate fields. The relationship between the two can only be mutual integration. In philosophical criticism on science, philosophy can establish a general way and mean of interpreting and developing science, thereby imparting a philosophical character to science; science can provide basic material support for the development of philosophy in the scientific transformation on philosophy, which gives philosophy a scientific charm.

If we say that philosophy is the knowledge that mankind pursues in search of universal rationality, then this is because the universal character of universal rationality clarified by philosophy determines that it must be a kind of universal light with the most universal explanatory power. In this regard, it can provide a certain degree of methodological norms for all levels and fields of human knowledge, through which all levels and fields of knowledge of humanity will be covered in varying degrees by the light of this general illumination. This is also consistent with the Platonic "participation" scenario. On the other hand, since science provides the basis for the transformation of philosophy, it will also allow the philosophy to manifest and "participate" the contents and spirit of science. In this sense, philosophy is not only on top of science but also in the science; science is not only under philosophy but also in the philosophy.

Here, we must also emphasize that the unity of such an inherent fusion of science and philosophy can also be fully demonstrated in the practical relationship between human philosophy and science development.

In fact, apart from the narrow path along epistemology, linguistics, and phenomenology, the development of human philosophy has another path. This is the development of philosophy itself that has been nurtured and demonstrated in the course of general scientific development. On the one hand, the construction of scientific rationality requires philosophical thinking and exploration. On the other hand, the progress of science opens the way for the development of philosophy.

One obvious fact is that, based on the development of experimental science since modern times, the development of Newtonian mechanics and the development of chemical atomism have deepened and developed the physical realism founded by ancient Greek philosophers, which is a philosophical ontology theory explaining the world is constituted by inseparable material particles; the energy field theories, like relativity theory, quantum mechanics, and modern cosmology, constitute the field 
energy realism, which is philosophical ontology theory explaining the world is constructed by the energy field without static mass; and the birth and development of contemporary information science provides a scientific basis for the ontological theory-dual existence and evolvement of matter and information. From this point of view, the study of philosophical ontology did not stop because of the rejection or suspension of those so-called specialized philosophers. On the contrary, with the development of human science itself, there is a certain mechanics existing within the process of scientific development itself. In the development of human science itself, metaphysics and physics has always been accompanying with each other.

Another equally obvious fact is that the development of human experimental science has also profoundly promoted the development of epistemology. The development of medicine, anatomy, physiology, neurophysiology, brain science, experimental psychology, and contemporary cognitive science has led to some philosophers in modern times using the relevant scientific research to study the processes and mechanics. For example, the British modern philosopher Francis Bacon (1561-1626) had also criticized the two extreme epistemologies of empiricism and rationalism, and he emphasized that the true philosophy should be a combination of scientific researches and human rationality. In order to criticize the extreme rationalist philosophy, he proposed that in the human mind structure, there are "four kinds of false impression"[7] theories that disrupt the mind and hinder scientific development; The French philosopher and scientist Rene Descartes (1596-1650), the father of "modern philosophy," once tried to find the basis of psychological activity from the physiological function, and proposed that the pineal gland is a combination of body and soul [8]; the French enlightening thinker Julien Offroy de La Mettrie (1709-1751) took advantage of the results of medical and anatomical physiology during his era to explain the content of human feeling and thinking ability from the perspective of human physiological characteristics, physical conditions, and the constructive nature of the human brain [9]. In the context of contemporary scientific development, many epistemological theories based on corresponding scientific development have been highlighted: e.g., embryological epistemology, experimental psychology, and behaviorist psychology, and the theories brain function and human cognition mechanism, cognitive sciences, and virtual epistemology, and information epistemology, and so on.

The above examples can fully demonstrate that at the different stages of the development of human science, there is also a corresponding natural philosophy. The corresponding natural philosophy not only makes an interpretation for the nature itself, but also carries out the nature-based scientific and philosophical exploration on human cognition.

In fact, if we take a closer look, the crisis of contemporary philosophy induced by the Western philosophy of consciousness looks like it stems from epistemology, but in fact, the roots of this crisis are buried in natural philosophy having nature as its basis.

We know that in the tradition of Western philosophy, the world is divided into three parts: God (including Plato's objective ideas), the material world, and the human mental world. In related doctrines, the material world and the mental world are separated from each other. The human spirit can only be derived from God and can only exist in form of "participating" the spirit of God. With the development of science, the God has been suspended by scientists, so that God has retreated gradually from science and philosophy. However, due to the inextricable separation of the opposition between the material and the mental in the Western philosophical tradition, the withdrawal of God makes the human spirit unable to find its external causes. Thus, the philosophers who hold extreme views can only seek to explain the causes of consciousness within the consciousness itself, and natural philosophy based on the nature itself can only be rejected consequently.

From this point of view, the key to solving the philosophical crisis is not to give up or reject the study of philosophical ontology or natural philosophy, but rather to reconstruct philosophical ontology having nature as its basis and reconstruct the doctrine of natural philosophy excluding the God as its foundation. The task to be accomplished by this new natural philosophy is how to regain the natural foundation of human consciousness after God has left the field. Here, one of the most tangible paths is 
how to describe the relationship between matter and consciousness as a process of interaction and mutual transformation. According to the evolutionary direction of the universe, and in accordance with the actual situation of cognition happening, a reasonable explanation on consciousness can be given. The existence of objective information, and the dual existence and evolution of matter and information proposed by contemporary philosophy of information just opened the way for such a natural philosophy.

\section{Developing Science and Philosophy in the Feedback Loop of the Interaction between Science and Philosophy}

A remarkable feature of the epistemology based on related theories of natural science is that they all combine science with philosophy, and combine the external factors of the subject with the internal structure and activities of the subject, rather than seeking explanation on the happening mechanism of cognition from some individual activity factors within the subject. Obviously, such kind of doctrines embodies the scientific approach of philosophy and the philosophical development of science. The methods they use are in accordance with the essence of the complexity methods provided by the theory of complex information systems. This is the method of the overall emergence of multiple synergies. This kind of method embodies the unity of nature and society, and the unity of nature, society, and human mental world. This is exactly the attitude and method of natural philosophy that reveals the logic of nature from the perspective of the nature itself.

The proponent of the complexity paradigm, the famous French scholar Edgar Morin (1921-) proposed a methodology of loop-back, contradiction (opposition and compatibility) and complementarity. He believes that two basic principles can be attributed to the complexity method: "The principle of dual-logics and the principle of the loop-back." He emphasized: "The principle and concept of opposition are complementarily connected in an inseparable manner", and the principle of the process of self-creation and self-generation of the universe and the principle that our understanding is a "loop of regression" [10]. Morin particularly emphasized that the interactions between opposing factors and among multi-factors create the complexity, and the method of describing such interactions process is a method of loop-back. He believes that the method of absolutely separating the opposition and diversity is an outdated principle of simplicity. He advocates to establish the general integration of loop-backs of the interactions within the steps of dual-elements opposition and multi-elements relationship in all fields and areas, including natural sciences, social sciences, arts, philosophy, the area of individual, society and race, the transdisciplinary field of physics, biology, anthropology and sociology, the relationship among order, disorder and organization, the relationship of science, politics and ideology, the interactions between the whole and its parts, the relationship of science, technology, society and the country, the relationships of subject and object, of mind and matter, of man and nature and of nature and society, etc. Moran believes that the corresponding comprehensive loop-back relationship reveals the intrinsic indivisibility and complexity existing between opposite-factors and multi-factors. It is the dynamic and cyclical universal interaction of this loop-back that embodies the general process and concrete mechanism of self-organization and development of things. In his view, complexity is constructed through the dynamic self-organizing activities of the loop-back between opposition and multiple factors. He wrote: "Descartes established a paradigm that has since been ruling the West all the time: the separation of subject and object, the separation of mind from matter, and the opposition between man and nature. If a new method can emerge from the principle of complexity, and grow and mature, then it may' give rise to revolution everywhere', even revolutionize the idea of revolution that is bland, aged and reactionary." [10]

From the point of view of complexity, science and philosophy are not necessarily separated. They regulate, contain, and integrate each other in the process of interaction. Philosophy is in science while science is also in philosophy. They are embedded together and form some dynamic feedback loops of interaction. Their development always influences each other, regulates each other, promotes each other, and transforms into each other. 
The unity of mutual influence, regulation, promotion, and transformation presented by science and philosophy in the inter-integration of interaction profoundly breeds and demonstrates the general ways of human knowledge development: the philosophilization of science and scientization of philosophy.

\section{Two Doctrines of Dogmatism}

Husserl denounced the naturalist attitude in general scientific research as dogmatism, and considered that the material world identified by naturalist attitudes is a transcendental and nisi world, which is non-existence world. Corresponding to this, he put the so-called "phenomenological epoché" that "excludes the entire world including all things, creatures, people, and ourselves", which is also called "pure consciousness"-intentionality itself, in the position of absolute existence. At the same time, he also believes that this pure consciousness essentially is independent of all natural existence; and it also can exist without having any other existing worlds as the precondition for its existence (Existenz). The real existence of nature cannot be a precondition for the existence of consciousness world, because the nature itself eventually becomes a related thing of consciousness; the nature exists only as something that is formed in a regular consciousness connector. He also said:

"..... what is given does not exist in spite of the continual consciousness of its own presence 'in person'." "Thus in every manner it is clear that whatever is there for me in the world of physical things is necessarily only a presumptive actuality and, on the other hand, that I myself, for whom it is there (when the 'part of me' belonging to the world of physical things is excluded) an absolute actuality or that the present phase of my mental processes is an absolute actuality, given by an unconditional, absolutely indefeasible positing." "Anything physical which is given 'in person' can be non-existent; no mental process which is given 'in person' can be no-existent." [4]

In this way, Husserl set an existence of transcendental ego having pure intentionality, which is independent and absolute existence, and starting from here he unfolded his entire phenomenological philosophy.

In fact, admitting the reality of self-consciousness and innate knowledge has always been a tradition of western philosophy. From the reminiscence of soul advocated by Plato (before 427-347), to Cartesian innate ideas, to Spinoza's "innate genuine concept" (1632-1677), to Leibniz's "innate ability" etc. When they talked about the origin of self-consciousness, it was always related to God. Although in Husserl's interpretation of "pure consciousness", "God" has retired (which is obviously the result of scientific development), but the priori self-consciousness has been reserved. Till phenomenology, the trend of philosophical understanding and scientific analysis on mind had been further strengthened.

However, in the experience of a person's specific cognition, the person's awareness, memory, thinking activity, and the person's actively subjective intentional activity are always carried on by the human body and the material brain of the person. Moreover, any significant change in the corresponding structure and activity of the physical body of human beings will bring about significant changes in the corresponding activities of human consciousness. In this sense, without talking about the origin of mind, the philosophical and scientific study on the content of mind is a kind of dogmatism. In this way, we are faced with two types of dogmatism: one is the dogmatism of naturalism and the other is the dogmatism of the philosophy of consciousness.

To overcome these two kinds of dogmatism tendencies, one of the best prospects is to unite natural ontology, epistemology, and cognitive constructivism, rather than building barriers among them or digging an insurmountable gap.

In fact, historically, ontology and epistemology are unified, but some philosophers are not willing to admit it; this has especially been the case since modern times, and some people have always rejected or suspended ontology. They have always been trying to limit their study within the scope 
of human cognition. It is believed that the analysis of purely conscious activities within human cognition can clarify the process and mechanism of human cognition, and on this basis, they are able to further clarify everything in the world and the universe. Husserl's phenomenology is as this. Then phenomenological theories about intentional activity and intentional construction appears. The linguistic turn of contemporary western philosophy also has a similar nature. They convert philosophical issues directly into linguistic analysis, simply attributing the clarification of human understanding and interpretation of the world itself to the analysis on a tool of human thinking-human language. Here, everything in the world, the complex physical and psychological activities of human beings, the diversity of people's understanding and practice, and the vivid processes and mechanism are all hidden away.

In detail, the method of seeking explanation of cognition from the consciousness activities within epistemology derives from the ontological separation of matter and consciousness. Since matter and consciousness are two poles of simple opposition, and since matter and consciousness are two different kinds of mutually opposing existences, then it is necessary to explain that the activity and nature of consciousness cannot be explained from the relevance of consciousness and matter. Since matter and mind are the two poles of separation, from the perspective of western philosophical tradition, the interpretation of the process and mechanism of consciousness cannot be clarified from its relevance to matter. This then leaves the only path of interpretation for the nature, process, and mechanism of consciousness that is sought within the isolated consciousness. This is the situation faced by philosophy of consciousness and mind in contemporary and modern western world. Kant's philosophy, illustrating an insurmountable gap between subject and object and a theory of a priori synthetic judgement, and Husserl's theory of intentional activity and intentional construction of pure consciousness, and the linguistic analysis of consciousness in philosophy of language and so on, are all inherit such a characteristic. Contemporary psychology, neuroscience, and brain science are trying to connect the consciousness or the mind to the body, which provides us an inspiration and strong empirical evidence to discuss the origin of consciousness. But there are mysterious psychological factors plaguing scientists and philosophers all the time. And those factors leave the ghost of dualism lingering.

The ontological doctrine that matter and mind are opposite and separated from each other directly leads to the epistemological theory that the object and the subject are opposite and separated. Western philosophy of consciousness claims that it can eliminate the dualistic opposition between subject and object through intentional activity and intentional construction. It is an attempt to replace the object of cognition with the subjective content of consciousness. Such an explanation cannot explain the relationship between the subjective content we know and some objects external to us, nor can we explain the reasons for the success or failure of our practical activities on the external things. Therefore, such a practice of setting up the relationship between the subject and the object only from the inside of the activity of consciousness does not really eliminate the dualistic opposition between the subject and the object, but merely evades the issue itself.

\section{The Resolution of Conflict: Information, Intermediaries, and Processes}

To break the opposite situation between nature and human, and between philosophy of nature and philosophy of mind, the key issue is to describe the relationship between matter and mind as a process of interaction and mutual transformation. This requires finding out an existing thing bridging matter and consciousness, because all interactions must have their intermediate links. Just imagine that, if an object is absolutely isolated from the outside and no intermediate is derived from it, then the object cannot interact in any way with the environment or other things. Modern science has also proved that the four basic interactions that sustain the order of the universe are achieved through the transmission of intermediary fields.

The intermediary of the interaction between objects derives from the interacting objects themselves, which is revealed by modern science. Any object can reflect or radiate energy field outwards through external or internal interactions. Because the corresponding energy field derives 
from the object itself, it can represent or show the property, characteristics and difference of the material thing that produce it through its nature and structure. And because of this, it can serve as a vehicle for the relevant information of the things that produce it. In addition, interactions at all levels can cause changes in the corresponding structures and states of the agents, and this change can be a coding of structure that generates or assimilate and dissimilate information in interactions. Because interaction is the way in which things exist, and the evolution of cosmic things does not have a starting point in time, in the existing nature, the structure of all objects is generated in the long evolutionary process, which also means that at the same time, all objects in the world are already informosomes whose related information is encoded by the structures generating them. In this way, all objects, and even the entire universe, are a dual-existence, which means that they are both material and informational. Based on the dual existence of matter (direct existence) and information (indirect existence) in the world, we can establish a new ontological theory. In order to distinguish it from the ontological doctrine in traditional philosophy, it is named information ontology. This ontological doctrine is the basic theoretical part of philosophy of information that has been established since 1980 by Wu Kun. According to the ontological theory of information, consciousness (or mind) is also information (indirect existence), but it is the subjective form of information, that is, the world of for-itself information and regenerated information. There is also an objective information world (a concept described in Kun Wu's philosophy of information) in the objective world. This is the in-itself information world. In this way, according to the information ontology, the world (existence) is composed of matter and information, and matter interacts with mind through the medium of in-itself information. In this way, the relationship between matter and mind is no longer simply pure opposite, but is linked through the intermediary of in-itself information. The relationship from matter to mind, and from mind to matter, can be described as a process of intermediary interaction and mutual transformation [11-13].

The philosophy of information advocated by Wu is very different from Floridi's philosophy of information. We believe that Floridi's philosophy of information is too narrow. First, the computational method is only a kind of measurement of information. So it cannot reveal the ontological features of information, and it is closely related to the intelligent agent. Second, we cannot deny the existence of environmental information that is independent from the intelligent agent. Floridi also mentioned the existence of such information. "We speak of environmental information when we wish to stress the possibility that data might be meaningful independently of an intelligent producer/informer." [14]. Dretske and Barwise and Seligman $[15,16]$ also researched environmental information. At last, based on the fact that information is a study on relationships, structures, and forms, it is not appropriate to limit the understanding of information to a computationalist approach. From the origin of concept of information, Aristotle's interpretation of form in ancient Greek philosophy is the interpretation of the relationship in the early history of philosophy [17]. The understanding of information in statistical physics, thermodynamics, and bioinformatics cannot be equivalent to the computationalist understanding on information. Otherwise, the Floridi's philosophy of information hinders us from acquiring a unified information concept and a unified information science paradigm [18].

But staying at the level of objective relationship is not enough to reveal the essential characteristics of information. In my opinion, the essential characteristics of information should be represented by more specific reflective relationships. This kind of reflection can be reflected in classical philosophy by the famous "signet-ring-stamps-impressions-in-wax". That is to say, I learned from the pattern traces left by the ring on the wax plate that the ring exists in part of the ring. Thus, we obtained information about the ring. In addition, from the word "information", I can also see the relationship between form and information, which could be seen as that we can obtain the information of the idea from the participated forms on the basis of Plato's theory. And we suggest that the content of stamp impressions is the real information, since it indicates the existence of the ring.

In western world, Marcia Bates defined the objective information in a way similar to Kun Wu's definition. We can compare them in the following: 


\section{Bates [19]:}

Information 1: Information is the pattern of organization of matter and energy.

$\mathrm{Wu}[20]$ :

Information is a philosophical category indicating indirect existence, and it is self-manifestation of existing ways and states of matter (direct existence).

Here, Bates advocates a matter-information doctrine like Aristotelian matter-form dualism, which is similar to $\mathrm{Wu}^{\prime}$ 's matter-information ontological theory. Bates uses patterns to indicate various relationships, both subjective and objective. And an object usually has many kinds of pattern. For example, a tree can have a physical relationship, as well as a chemical relationship or biological relationship or environmental relationship, and so on. Those relationships are its different patterns, and it reflects the existence of its related things.

All in all, we advocate the existence of objective information, and also advocate that the objective information is more fundamental than subjective information and can work as an intermediary between matter and mind (the high-level activity of subjective information).

\section{Multi-Dimensional and Multi-Polar Complexity Features of Human Cognition Activities}

The establishment of information ontology provides a unified foundation for the transformation of all other domains of philosophy and also provides a unified basis for the transformation of epistemology. It is necessary to establish a new information epistemology theory accordingly.

Based on the investigation of information epistemology, human cognition activities are the emergence of multi-dimensional and multi-polar complexity with the most novel and innovative features. "As a multi-dimensional, multi-polar, complex and comprehensive construction emergence, the generation of consciousness is both internal and external to the consciousness, as well as a product of interaction between the internal and the external; it is both subjectively presented and potentially regulated, as well as a product of interaction, transition and transformation between presentation and regulation; it is both subjectively active and objectively passive, as well as a product of unification between activity and passivity; it is both natural and humane, as well as a product of interaction between nature and human; it is both individual and social, as well as a product of interaction between individual and society; it is both directly presented and indirectly intermediate, as well as a product of construction and virtualization in the interaction between the direct and the indirect; it is both present and historical; as well as a product of mutual transformation and generation in the interaction of the present and the past; it is physiological, psychological and behavioral, as well as a product of synergistic interaction of the three aspects; it is conscious, subconscious and unconscious, as well as a product of interaction and transformation of the three items." [21].

In his philosophy of information, Wu Kun proposed a "Epistemology of Information Intermediaries" (Wu Kun, 1984), which uses the construction of multi-level mediators and virtual activities to explain the general mechanism and processes of human cognitive activities. There are four corresponding mediums during the cognitive processes (Wu Kun, 1989): the objective information field, the neurophysiological structure of the subject itself, the cognitive structure that the subject has constructed first, and the materialized means of the subject's cognition (tools, instruments, facility). In addition, the complexity of human cognition not only lies in the current multi-dimensional intermediary construction and virtualization activity, but also lies in its natural evolution and socially-generated historical process. This includes both the natural history of the subject's physiological structure and the evolution and construction of the social history. It also includes the genetic ability of the subject's cognitive structure and the role of the natural, social, and cultural information environment. It also includes the history of the emergence and development of materialized tools which is consistent with the evolution of human social abilities [21].

From this point of view, the ontological and epistemological aspects of philosophy and other areas of philosophy cannot be separated, and all other fields of philosophy must be based on ontology. 
The rejection or suspension attitude towards ontology of western contemporary philosophy looks like making epistemology independent of ontology. Actually, its essence is the contradiction and separation of matter and mind. Due to the lack of necessary links between matter and mind, Western contemporary philosophy has to retreat to the inner world, simply seeking to interpret consciousness itself within the conscious activities.

On the basis of information ontology and information epistemology, Kunian philosophy of information has also developed a series of theories, including information evolution theory, information production theory, information society theory, information value theory, and information thinking theory.

From this perspective, since the 1980s, the philosophy of information established and developed in China firstly is a natural philosophy that adheres to naturalistic attitudes. However, this natural philosophy in the process and mechanism of its natural evolution explains human beings, human mind and human society. Therefore, the philosophy of information in China is a kind of meta-philosophy or supreme philosophy. This system undoubtedly has a brand-new style of natural philosophy. At the same time, this philosophy can better reflect the philosophical spirit of the information age.

Author Contributions: K.W. conceived of the main ideas and wrote the manuscript. Z.W. provided some supportive arguments, supplemented some details and did the English Translation work.

Funding: This research received no external funding.

Acknowledgments: We thank the two reviewers for making important and precious suggestions on modification of this paper. And we also thank editors for their hard work.

Conflicts of Interest: The authors declare no conflict of interest.

\section{References}

1. Feng, Q. Great Dictionary of Philosophy (Part 1); Shanghai Lexigraphical Publishing House: Shanghai, China, 2007; p. 323.

2. Wu, K. The Logic of Nature; Northwest University Publishing House: Xi'an, Shaanxi, China, 1990.

3. Wu, K. The New Dialectics; Xi'an Jiaotong University Publishing House: Xi'an, China, 2003; pp. 3, 6.

4. Husserl, E. Ideas Pertaining to a Pure Phenomenology and to a Phenomenological Philosophy; Kersten, F., Translator; Martinus Nijhoff Publishers: Leiden, The Netherlands, 1983; pp. 102-103.

5. $\mathrm{Wu}, \mathrm{K}$. The Hierarchy and Hierarchical Transition of Universal Rationality-On the Internal Unity of Science and Philosophy. J. Northwest Univ.-Sci. Anthol. Youth 1991, Supplement, 11-17.

6. $\mathrm{Wu}, \mathrm{K}$. Discussion on the Relationship between Science and Philosophy. Sci. Technol. Dialect. 2004, 1, 1-3.

7. The Office of Western Philosophical History in Philosophy Department of Peiking University. The Selected Readings and Western Philosophical Works (Volume 1); The Commercial Press: Beijing, China, 1981; pp. 358-359.

8. Feng, Q. Great Dictionary of Philosophy (Part 2); Shanghai Lexigraphical Publishing House: Shanghai, China, 2007; p. 1692.

9. Julien, L.M. L'homme-Machine; Gu, S.-G., Translator; The Commercial Press: Beijing, China, 2009; pp. 17-18, 26-28, 54-55.

10. Edgar, M. La Methode: La Nature de la Nature; Wu, H.-M.; Feng, X.-J., Translators; General Introdution; The Peiking University Publishing House: Beijing, China, 2002; pp. 1-2, 2-5, 19.

11. $\mathrm{Wu}, \mathrm{K}$; Brenner, J. Philosophy of Information: Revolution in Philosophy: Towards an Informational Metaphilosophy of Science. Philosophies 2017, 2, 22. [CrossRef]

12. $\mathrm{Wu}, \mathrm{K}$. The Development of Philosophy and Its Fundamental Informational Turn. Information 2015, 6, 693-703. [CrossRef]

13. $\mathrm{Wu}, \mathrm{K}$. The Essence, Classification and Quality of the Differnet Grades of Information. Information 2012, 3, 403-419. [CrossRef]

14. Floridi, L. Information: A Very Short Introduction; Oxford University Press: London, UK, 2010; p. 32.

15. Dretske, F.I. Knowledge and the Flow of Information; The MIT Press: Cambridge, MA, USA, 1981.

16. Barwise, J.; Seligman, J. Information Flow: The Logic of Distributed Systems; Cambridge University Press: Cambridge, UK, 1997. 
17. Information, SEP. Available online: https://plato.stanford.edu/entries/information/ (accessed on 20 July 2018).

18. Wang, Z. About the Nature and Unification Relationship of Information Science and Information Philosophy. J. Intell. 2018, 37, 114-121.

19. Bates, M.J. Information and Knowledge: An Evolutionary Framework for Information Science. Inf. Res. 2005, 19. Available online: http:/ / www.informationr.net/ir/10-4/paper239.html (accessed on 20 July 2018).

20. Wu, K. Philosophy of Information-Theory, System and Method; Commercial Press: Beijing, China, 2005; pp. 45-46.

21. Wu, K. Discussion on the Complexity Characteristics of Multi-dimensional and Comprehensive "Emergence" in Noegenesis-A Critique on the Single-dimensional and Simple feature of Husserlian Phenomenology Reductionism. J. Hebei 2014, 4, 25-30.

(C) (C) 2018 by the authors. Licensee MDPI, Basel, Switzerland. This article is an open access article distributed under the terms and conditions of the Creative Commons Attribution (CC BY) license (http:/ / creativecommons.org/licenses/by/4.0/). 